\title{
E A TERRA CONTINUA A TREMER: 1755 - O GRANDE TERREMOTO
}

\author{
Flavio Felicio Botton ${ }^{1}$
}

\begin{abstract}
RESUMO: Miguel Real e Filomena Oliveira, dramaturgos portugueses contemporâneos, recriam, em uma peça histórica, a sociedade lusitana do século XVIII, em um momento crucial para a história europeia, o do terremoto de 1755, em Lisboa. O que esse trabalho pretende é, por meio da leitura analítica da peça 1755 - O Grande Terremoto, identificar o elemento da história contemporânea portuguesa que a obra dos autores pretende iluminar.
\end{abstract}

PALAVRAS-CHAVE: teatro português; Marquês de Pombal; terremoto de Lisboa.

ABSTRACT: Filomena Oliveira and Miguel Real, Portuguese contemporary playwrights, recreates, in a historical play, the Lusitanian society of the eighteenth century, at a crucial moment in European history, the time of the earthquake of 1755 in Lisbon. This paper intends, through analytical reading of the play $1755-O$ Grande Terremoto, identify the element of contemporary Portuguese history that the work of the authors intended to illuminate.

KEYWORDS: Portuguese drama; Marquis de Pombal Lisbon earthquake.

\section{Introdução}

Era dia de Todos os Santos, primeiro de novembro de 1755, quando um terremoto de enormes proporções estremeceu Lisboa. Grande parte da cidade foi arrasada. Como era hora de missa, o povo, reunido nas igrejas, sofreu ainda mais com os desmoronamentos que acabaram por matar milhares de pessoas.

O episódio, uma tragédia que sensibilizou toda a Europa, é tido como ponto marcante na história portuguesa, assim como um evento crucial na carreira política de uma das mais controversas figuras públicas do país, Sebastião José de Carvalho e Mello, o conde de Oeiras e, para a posteridade, conhecido como Marquês de Pombal.

Após o terremoto, ou com a ajuda dele, Pombal se desfez de seus maiores inimigos, levando à execução e à humilhação pública os mais influentes membros da nobreza e da igreja lusitana.

O enorme sismo de Lisboa acabou por desencadear não só uma reforma nas estruturas políticas portuguesas, mas também uma discussão em torno da figura de Deus e das filosofias em voga até então, como se deu entre Leibniz, Voltaire e Rousseau.

Recentemente, em 2006, Miguel Real e Filomena Oliveira levaram ao palco um painel da sociedade portuguesa da época do grande terremoto. Personagens da nobreza,

\footnotetext{
${ }^{1}$ Professor de Literatura Portuguesa e História da Arte da Universidade do Grande ABC, mestre e doutorando em Literatura Portuguesa pela USP. Autor de Que Enigma Havia em Teu Seio: Ensaios sobre Artes Plásticas e Literatura (2010), publicado pela Editora Todas as Musas.
} 
do clero e do povo são revividos para mostrar o embate histórico entre as classes sociais e as reformas levadas a cabo por Pombal. Em entrevista à revista Todos os Nomes, de junho de 2008, Miguel Real asseverou que a finalidade do teatro histórico seria, entre outras, não a de reproduzir a história, mas, sim, a de iluminá-la, proporcionando um maior entendimento do passado e do presente, por meio de episódios históricos.

O que esse trabalho pretende é, por meio da análise da peça 1755 - O Grande Terremoto, identificar o elemento problemático da história portuguesa que o teatro de Real e Cabral pretende iluminar. Para cumprir essa tarefa, será necessário, além da análise da peça, estudar a situação da sociedade portuguesa durante o reinado de D. José I, o terremoto de 1755 e as suas consequências históricas, sociais e filosóficas.

\section{Portugal à sombra do Iluminismo: Pombal, o terremoto, as reformas}

Historiadores concordam em dizer que o reinado de D. João $\mathrm{V}$ foi de extrema suntuosidade e frivolidade e que, com os recursos das minas de ouro, era possível ter dado ao país uma forte marinha mercante e de guerra, indispensáveis ao comércio como era estruturado no período. Ao invés disso, os fidalgos, que glorificavam o rei, "usavam espadins de ouro constelados de pedras preciosas" (SOARES, 1983, p. 56) e o povo pouco usufruía disso tudo.

No dia da morte de D. João, 31 de julho de 1750, após 61 anos de vida e 46 de reinado, como que prenunciando o que iria ter palco em diante, um leve tremor de terra atinge a cidade de Lisboa (PAICE, 2010).

D. José I, filho e sucessor de D. João V, escolheu o governo, e entre os novos funcionários estava Sebastião José de Carvalho e Melo, cuja nomeação desagradara desde o princípio à nobreza velha, já que ele era "fidalgo de cepa provinciana" (SARAIVA, 1995, p. 247). Muito rapidamente, o novo ministro acabou por dominar os outros ministérios.

Apesar das muitas controvérsias que cercam os atos de Sebastião José, uma afirmação é inequívoca: o terremoto de 1755 foi o ponto de virada da carreira do ministro de D. José I. Oliveira Martins, um dos historiadores a descrever a associação entre Sebastião José e o terremoto, assim o faz: "O terramoto fez-se pois homem, e encarnou em Pombal" (MARTINS, 1988, p. 172). 
Aquele primeiro de novembro de 1755 começou como uma bela manhã de outono, quando um assustador estrondo seguido de um imenso tremor assolou a capital portuguesa.

Em Lisboa, ruíram cerca de dez mil construções, e tesouros públicos e particulares se perderam em meio às ruínas. Foram ao chão edifícios públicos, conventos e o próprio palácio do rei. A mais terrível consequência, contudo, foi a perda humana. As cifras mais confiáveis giram em torno de trinta a quarenta mil mortos apenas na capital.

A participação do ministro foi decisiva tanto no resgate da cidade, quanto na sua reconstrução. As palavras abaixo, de Oliveira Martins, resumem a frase atribuída a Sebastião José, “cuidar dos vivos e enterrar os mortos":

\begin{abstract}
Quando a cidade ardia e desabava ainda nos primeiros dias de novembro, Pombal, (...) preveniu as consequências da desgraça funesta. (...) Já se comiam os cães, os gatos, os ratos (...) Pombal construiu albergues para os dispersos; organizou a tropa em companhias de coveiros; (...) comprou trigos (...) proibiu a saída de víveres; defendeu as praias contra os argelinos (...) prendeu os mendigos e vadios; enforcou sumariamente (...) os ladrões e incendiários, deixando-lhes as cabeças pregadas no patíbulo, para exemplo. Tamanha força aturdia o povo simples; tanto ou mais do que a fúria do cataclismo. (...) (MARTINS, 1988, p. 172)
\end{abstract}

Da hecatombe nasceu, então, o poder de Pombal, cuja força seria capaz de subjugar os inimigos mais perigosos e poderosos, fizessem eles parte de qualquer um dos grupos que formavam a sociedade portuguesa.

O primeiro grupo a sentir a mão de ferro de Sebastião José foi a plebe do Porto. Trata-se do motim contra a companhia das Vinhas do Alto Douro, em 1757. O ministro envia uma alçada que prende e pune de maneira extremamente violenta os supostos revoltosos contra a autoridade real que havia criado a companhia.

Em seguida, começam a ser articulados os estratagemas que viriam a derrotar as outras duas classes e a oportunidade para livrar-se dos nobres que tanto desprezavam Sebastião José se deu após um atentado contra a vida do rei.

Dom José voltava de um encontro com sua amante, a marquesa de Távora nova, quando foi emboscado e ferido de forma razoavelmente grave. Segundo Maxwell (1996), o rei indica muito tardiamente uma comissão para averiguações. Foram presos o duque de Aveiro e seu filho, Conde de Atouguia, e os membros da família Távora. 
Em 4 de janeiro, é nomeada a Suprema Junta da Inconfidência, responsável pelo julgamento, que será presidida por João Pacheco de Vasconcelos, o mesmo que afligira os insurrectos do Porto, mas obviamente dominada por Sebastião José.

Após isso, o processo corre muito rápido, a ponto de se dizer, conforme Azevedo (1990), que, quando o arrazoado de defesa dos réus ficou pronto, a sentença e as penas de cada acusado já estavam escritas.

A 12 de janeiro, apenas alguns dias depois, deu-se a sentença dos prisioneiros. Seus crimes foram definidos como de lesa-majestade, traição e rebelião contra o rei e o Estado. Aos juízes, dada a gravidade do crime, foi permitido impor castigos que não estavam na lei ordinária. Segundo Maxwell,

O duque de Aveiro foi condenado a ser despedaçado vivo: teria os braços e as pernas esmagados, seria exposto em uma roda para todos o verem e queimado vivo, e suas cinzas seriam jogadas no mar. $\mathrm{O}$ marquês de Távora velho teria a mesma sorte. A marquesa de Távora seria decapitada. As pernas e os braços dos outros membros da família seriam quebrados na roda, mas antes eles seriam estrangulados, diferentemente do marquês e do duque, cujos membros seriam quebrados com eles vivos. (MAXWELL, 1996, p. 79)

Mais uma vez, com extrema presteza, a sentença foi cumprida no dia seguinte em um patíbulo montado em Belém. Embora de grande crueldade, a punição dos conspiradores não destoava do usual na época. O que realmente impressionava no caso era a posição social das vítimas, pois o "duque de Aveiro (...) era o nobre mais poderoso de Portugal depois da família real (...). O marquês de Távora velho era general e diretor geral da cavalaria e havia servido como vice-rei da Índia” (MAXWELL, 1996, p. 88).

Segundo os depoimentos estudados por Edward Paice, "O efeito salutar das execuções reduziu o resto da nobreza, nas palavras de Benjamin Farmer, a 'uma condição pouco acima de servos domésticos"” (PAICE, 2010, p. 237).

Ironicamente, a atuação do ministro no julgamento acabou por domar os mais poderosos nobres do país e valeu a Sebastião José a sua própria entrada no mundo da fidalguia. O rei concede-lhe o título de Conde de Oeiras.

Desde o princípio, os boatos que se espalharam imputavam o atentado aos Távoras, por conta do notório adultério do rei com a marquesa nova, ou ao Duque de Aveiro, por conta de suas divergências com o rei. Porém, rapidamente, entrou-se a dizer que os jesuítas tinham sido os instigadores do crime (AZEVEDO, 1990). 
O que despertou tal rumor foi o fato, suspeito decerto, de que nenhum padre da Companhia de Jesus compareceu às missas celebradas em causa do pronto restabelecimento do rei (MAXWELL, 1996). A intenção de Sebastião José era mostrar que, sem o auxílio dos jesuítas, nada teria acontecido. Assim, "No dia anterior à espetacular punição dos aristocratas (...) pelo atentado regicida, oito jesuítas foram presos por uma suposta cumplicidade, entre eles o Padre Gabriel Malagrida, missionário e místico jesuíta" (MAXWELL, 1996, p. 89). Pombal pessoalmente denunciou Malagrida, confessor da Marquesa de Távora, à Inquisição.

Assim, entre 1755 e 1760, foram subjugados povo, clero e nobreza, o que permitiria a Sebastião José de Carvalho e Melo, Conde de Oeiras, exercer sem travas o poder absoluto. Segundo Oliveira Martins:

O terramoto durou cinco anos $(1755$ - 1760) e subverteu as ruas e as casas, os templos, os monumentos, as instituições, os homens, e até as suas ideias E sobre as ruínas e destroços da cidade maldita, levantouse a Jerusalém do utilitarismo burguês (...) (MARTINS, 1988, p. 172).

Em meio a todos esses fatos, continuava a reedificação de Lisboa, embora o verbo "reedificar" não agrade a muitos historiadores, que preferem dizer que foi erguida uma nova cidade no lugar da antiga. Essa afirmação, que será importante para o pensamento histórico de Miguel Real, denota uma sociedade com dificuldades de construir e evoluir a partir de um ponto conquistado. Já o mesmo Oliveira Martins aponta que a sociedade portuguesa vai de revolução em revolução ${ }^{2}$, destruindo o que antes havia para sempre construir algo novo a partir do zero. "Árvore sem raízes”, diz Martins em que:

(...) qualquer sopro abala a construção inteira e, depois de cada terremoto, os estadistas, perante a ausência da vida coletiva, podem livremente seguir os impulsos do seu próprio pensamento. A sociedade, estéril e muda, somente pede alguém que governe e a faça feliz; recebe tudo, aclamando os audazes (MARTINS, 1988, p. 173).

Em outras palavras, sem a efetiva participação popular não há evolução social, dado que as sociedades complexas não admitem saídas simplórias, sem a discussão e a comunicação entre todos os envolvidos.

Sebastião José de Carvalho e Melo, conde de Oeiras, foi sagrado em 1769 com o título com que passaria para a posteridade, Marquês de Pombal. Porém, com a morte do

\footnotetext{
${ }^{2}$ Martins aponta como decisivos exemplos desse fato, os acontecimentos de 1640, 1755 e de 1834.
} 
rei, ele é afastado para as suas propriedades e, posteriormente, proibido de se apresentar na presença da rainha D. Maria.

Assim, de revolução em revolução, a destruição do já existente havia acontecido com Sebastião José e, depois, aconteceria com D. Maria I, sucessora de Dom José, que, ao assumir o trono, daria a impressão de que tudo "era como se Dom João tivesse voltado do túmulo para governar de novo" (PAICE, 2010, p. 262).

Esses fatos podem ser explicados pela expressão de Paice (2010), ao asseverar que as reformas pombalinas teriam sido, na verdade, um embaralhar de cartas. Ou seja, onde antes estavam os judeus, foram colocados os jesuítas, que cederam o seu espaço aos oratorianos. A burguesia comercial ocupou as cadeiras reservadas aos nobres. Entretanto, o povo pouco aproveitou de todo o processo.

Apesar disso, o legado do consulado pombalino é inquestionável: reformas na educação, fortalecimento do comércio e revitalização da aliança com a Inglaterra e a reconstrução de uma cidade comercial que poderia ter se atrofiado facilmente após a catástrofe.

\section{1755, o Grande Terremoto em cena}

A peça 1755, o Grande Terremoto está dividida em duas partes, contendo a primeira 8 , e a segunda, 12 cenas, todas com títulos explicativos ou sintetizadores de seus conteúdos. O entrecho mostra-nos esse conturbado momento da história, a promoção e a decesso de Sebastião José, como ministro do rei. Há dois fios de enredo: um que segue as personagens das classes altas e, outro, que participa da vida do povo. Em alguns eventos, os dois fios acabam por se cruzar.

Na primeira parte da peça, temos as descrições da sociedade portuguesa e de seus conflitos antes do terremoto, que irá surgir em cena ao fim dessa parte, aproximadamente o meio da peça, o que reafirma o seu caráter de "divisor de águas". Ou seja, entende-se que, nesse ponto, a história do país se separa, havendo um Portugal antes e outro depois do terremoto.

Já na segunda parte, sobressaem-se as atuações do Marquês de Pombal e suas tentativas de reconstruir a cidade de Lisboa, assim como a de reformar a mentalidade portuguesa, além do atentado que levará os Távoras e o Duque de Aveiro à morte e à perseguição aos jesuítas. 
Permeando todos esses conflitos, há a presença de personagens do povo, sendo a mais importante, Mariana, que se sabe, ao fim, filha bastarda de D. José I.

Dada a grande gama de possibilidades, procuramos escolher uma linha de leitura analítica que nos levasse a alcançar os objetivos propostos na introdução desse trabalho. Sendo assim, procuraremos analisar as descrições feitas na peça em relação aos três grupos lá representados e os conflitos que se dão entre eles. O primeiro seria a nobreza, representada pelas personagens dos Marqueses de Távora, velho e novo, e da Marquesa velha, além do Duque de Aveiro e do Conde de Unhão. Em alguns pontos, a esse grupo se aliam alguns eclesiásticos, como o Padre Malagrida. O segundo grupo seria o de Pombal, composto apenas por ele próprio e por Dom Luís da Cunha. E, por fim, o grupo do povo, representado pelas prostitutas do botequim da Rosa, em especial por Mariana.

O primeiro grupo, o da nobreza, pode ser descrito por quatro características e uma preocupação. Seus membros, em destaque os masculinos, são frívolos, atrasados, inoperantes e lascivos. Acentua-se na peça a frivolidade da nobreza criada em tempos de D. João V, como se pode perceber na fala de Michaela, uma das prostitutas, fingido comiserar-se pelo Conde de Unhão, obrigado a trabalhar pelo ministro:

(...) logo o meu pequerruchinho a trabalhar, com mãos tão delicadas, unhas envernizadas com goma-laca de Macau, anéis de brilhantes de Ceilão na mão esquerda, de ouro do Brasil na mão direita, rubi olhode-pomba de Goa no peitilho, bota pele de gamo africano, tacão de sândalo do Timor, espadão de ferro de Ceuta (...). (REAL, 2006, p. 44).

Percebe-se a presença de elementos que representam o passado glorioso português, o das navegações que levaram o império a terras tão distantes (Macau, Brasil, Goa, Ceuta etc.), agora reduzidos a enfeites e adereços para o traje do nobre, usados apenas para impressionar uma prostituta.

A inoperância e atraso do grupo referem-se principalmente à inatividade produtiva. O que poderia, por exemplo, levar o país a um novo estágio econômico e a criação de fábricas, é visto com desprezo e desconfiança pelos nobres, por motivos absolutamente vazios.

Já a lascívia não carece de maiores exemplos que os nobres compondo pares com as prostitutas no baile real ou mesmo com elas copulando em meio às ruínas da cidade, enquanto as suas esposas limpam o sangue dos feridos (REAL, 2006, p. 86 e p. 151). 
Se essas são as características do grupo, uma só é a sua preocupação: a perda do poder. A apreensão quanto à ascensão do ministro está sempre presente, desde o princípio, nas palavras do marquês de Távora Pai: “(...) Sebastião José é um burguês. O seu avô falsificou o título. (...) É descer muito baixo entregar o poder ao descendente do padre Sebastião da Mata Escura (...)” (REAL, 2006, p. 35).

O segundo grupo, muito mais coeso que o primeiro, é formado pelas personagens planas do Marquês de Pombal e Dom Luís da Cunha. Suas únicas motivações são a modernização do país e a substituição de uma classe dominante por outra.

Ambas as personagens descrevem com ênfase a decadência da aristocracia. Tomese como exemplo o relato de Pombal ao Provincial dos Jesuítas: “(...) a tradição da nobreza portuguesa é (...) lutar e conquistar, descobrir e explorar, colonizar e missionar. E hoje? Brigam com touros no Campo de Santana (...). Já nem espada sabem empunhar (...)" (REAL, 2006, p. 61).

As reformas empreendidas por Pombal e Cunha ficam explicitamente mais intensas após o sismo de Lisboa e ainda mais céleres depois da condenação dos oponentes do grupo pelo atentado ao rei. O próprio Malagrida, já rumo à loucura profética, proclama à rainha-mãe, quase que parafraseando a expressão já citada de Oliveira Martins: “O terremoto caiu sobre os homens” (REAL, 2006, p. 178). Exemplo desse processo de aceleração das reformas está no encontro entre Pombal e o rei Dom José. O ministro vai elencando as propostas e o rei apenas responde, por mais de cinco vezes, como um autômato: "Muito bem” (REAL, 2006, pp. 188-191).

Essas reformas, em conjunto com a reconstrução de Lisboa e com a eliminação dos oponentes, mostram-nos uma espécie de renascimento da cidade para uma nova classe dominante: "Pombal: Sinto-me feliz com essas mudanças, é uma nova Lisboa que está nascendo" (REAL, 2006, p. 156). Sem aristocratas ou jesuítas, a nova sociedade elimina algumas de suas características marcantes e assume outras bastante diferentes. Repare-se, na descrição feita abaixo, que nada é aproveitado, tudo é substituído:

Marquês de Pombal: Uma nova Lisboa nasce, uma Lisboa racional, simples, linhas retas e quebradas, nada dos labirintos medievais, uma Lisboa burguesa, geométrica, uma Lisboa europeia, comerciante e industrial (...) como uma cobra que expulsará de si a antiga pele velha, carcomida pelo tempo (silencio breve). Quem lhe vestir essa pele velha, morrerá com a Lisboa antiga (REAL, 2006, p. 164). 
Atente-se para o fato de que uma classe dominante desponta com a nova cidade e, em nada, tira-se proveito do passado, pois essa observação será importante para a conclusão dessa leitura.

Chegamos então ao último grupo social representado na peça de Real e Oliveira, o povo, que contribui de maneira diligente na caracterização dos outros dois grupos.

Por exemplo, uma moça do povo fala, no botequim da Rosa, com o marquês de Távora filho, definindo a aristocracia, como aquele que não sabe o que é trabalho.

Quanto ao grupo de Pombal, as descrições feitas por parte de personagens do povo não são diferentes. Para construir de antemão a relação entre o ministro de Dom José e a plebe, os autores da peça optam por um anacronismo. Assim, o motim do povo do Porto que, como se sabe, ocorre em 1757 - após o terremoto portanto -, na peça é deslocado para antes dele. Ainda no botequim da Rosa, conversam sobre o levante, um carregador, um galego e um marinheiro:

Galego: (...) Todos na rua gritando. "O vinho é do povo! Muerte a la Companhia das Vinhas do Alto Douro!". Chegou a tropa. Mulheres e niños, todos corridos pela tropa.

Carregador: Raça de ministro nos havia de sair. Faz a Companhia para controlar o vinho e desgraçar o povo.

Marinheiro: Dizem que o vinho não tinha qualidade, que Londres protestava (...)

Carregador: É , mas foram todos presos, essa é que é a essa. (...) Vamos nós beber um copo antes que o Ministro proíba o vinho ou venha prender quem bebe! (REAL, 2006, p. 53).

Repare-se que as elites não fazem menção ao povo, mas as descrições acima fornecem a pista que elucida o fato: tanto o grupo dos nobres, quanto o de Pombal, ou desprezam o povo ou tiram proveito dele.

Assim, antes do terremoto, o povo sofria já com a brutalidade da classe dominante; era expropriado de forma violenta, seja pelos nobres, seja pela nova burguesia comercial. Depois do terremoto, a situação muda, mas apenas para os nobres, que começam a caminhada à descensão social, e para a burguesia, que segue, sem os empecilhos da aristocracia, rumo ao comércio modernizado.

Portanto, mesmo após o terremoto, o povo continua na mesma condição. Mariana é presa e as prostitutas são expulsas da casa cedida pelo Conde de Unhão. A cena da expulsão das prostitutas é significativa:

Conde: (...) pacóvios parlapatões, julgam que a casa é de Mariana. Como se eu desse a casa do meu bisavô das Índias a uma puta. (...) 
(nunca parando de rir) A Mariana saiu do notário e o escrivão rasgou o registo falso (...).

Michaela: Então a casa nunca foi de Mariana.

Conde: (sério) Nunca, nunca de nunca. (para os guardas) Ponhamnos daqui a andar, e depressa (...). (REAL, 2006, p. 201)

Se pensarmos a casa como índice simbólico do país, veremos que a nação, de fato, mesmo com a alteração das elites, nunca pertenceu ao povo. Lembremos ainda que Mariana, personagem mais expressiva do povo português é, na verdade, filha bastarda de Dom José, quando ela deveria ser, como símbolo do povo, filha legítima do rei, "pai da nação".

Podemos, então, retomar a fala de Pombal, notando que uma "nova Lisboa nasce" (REAL, 2006, p. 164), mas apenas para a nova classe dominante e não para o povo.

A peça chega ao seu epílogo de maneira muito semelhante ao que foi mostrado no nosso resumido panorama histórico. Como se disse antes, ao feitio de cartas embaralhadas, o jogo do poder se refaz novamente com outra mudança radical e pouco aproveitamento do que se construiu.

Morre Dom José, assume Dona Maria I e as antigas elites, nobreza e clero, simbolizado pelo rosário nas mãos da rainha, retomam o seu lugar:

D. Maria I: (ostentando o rosário entre as mãos, ameaçadora) Será também em memória de meu pai real que, após a sua morte, farei ressurgir com honra e orgulho o que o Ministro chama de Portugal velho. Farei com que Portugal se esqueça do nome de Sebastião José de Carvalho e Melo. (REAL, 2006, p. 213)

Da mesma maneira que Pombal, trabalhará Dona Maria, ou seja, não evoluindo ou reconstruindo, mas radicalmente rompendo com o passado. Nas palavras do ministro, percebe-se que há concordância com o método, embora discorde do conteúdo das reformas: "Pombal: Em Portugal as reformas ou são violentas, escritas com sangue, ou não se fazem, Portugal nada consegue pacificamente" (REAL, 2006, p. 213).

Porém, sejam aristocratas ou burgueses a compor a elite do país, a condição do povo não se altera. Tanto que, ao fim da peça, as personagens das prostitutas, que antes gravitavam em volta do conde e de outros nobres, aparecem ao lado do, até então, sisudo Luís da Cunha, como se vê na rubrica: "Saem os três, rindo e galhofando, Michaela e Lolita, de braço dado com D. Luís da Cunha” (REAL, 2006, p. 212). 


\section{Cartas embaralhadas}

Como foi proposto anteriormente, a intenção desse trabalho era procurar identificar o elemento problemático da história portuguesa que se faria elucidar por meio do teatro histórico de Oliveira e Real.

A peça analisada traz um tema recorrente na obra dos autores, em especial na obra de Real. Portugal seria, em grande plano, o centro das preocupações do autor. Obviamente, para se entender um país é preciso analisar e compreender a sua história, e, para realizar tal tarefa, percebemos, por meio da leitura de sua obra, que o autor considera alguns pontos-chave para alcançar a compreensão do país. Tais pontos estariam concretizados em algumas figuras históricas portuguesas, tais como Viriato, Vieira e Pombal.

Miguel Real dedicou um ensaio a Vieira ${ }^{3}$, um livro a Pombal ${ }^{4}$ e pulicou ainda o volume A Morte de Portugal (2007), em que se contextualizam essas figuras na história do país, que estaria, segundo Real, vinculada a quatro momentos que viriam moldar o Portugal contemporâneo ou o próprio modo de ser português.

O primeiro, denominado pelo autor de "Complexo Viriatino", estaria ligado a Viriato e à fundação heroica dos pais, na figura do homem quase lendário que, apesar da sua fragilidade militar, vence as legiões romanas, seus mais fortes oponentes. Seria ele um símbolo contra a "prepotência do ocupante estrangeiro" (REAL, 2007, p. 12).

O segundo momento estaria representado pelo "Complexo Vieirino", que teria início após o reinado de Dom João III, Alcácer-Quibir e a decadência do império. Nesse momento, teria sido anunciada à nação a ideia do "futuro como o regresso anunciado às glórias do passado, agora sob o divino nome de Quinto Império” (REAL, 2007, p. 13).

Já a designação de "Complexo Pombalino" viria a nomear o terceiro momento, que é caracterizado pela humilhação nacional que precisaria imperiosamente recorrer às luzes europeias, dada a incapacidade nacional de seguir por suas próprias pernas.

O último dos complexos históricos descritos pelo autor seria o "Canibalismo Cultural”. Aqui, desenvolve-se ainda mais a noção de que o país não pode caminhar com a sua cultura, que é preciso devorar cada "nova doutrina emergente destruindo e esmagando a(s) anterior(es), estatuídas estas como inimigas de vida e de morte, alvos a abater, e as suas obras como negras peçonhas a fazer desaparecer" (REAL, 2007, p. 15).

\footnotetext{
3 "Padre Antonio Vieira e o ano de 1666" (1998, separata da revista "Vária Escrita", Sintra).

${ }^{4}$ O Marquês de Pombal e a Cultura Portuguesa (2006), Editora Quidnovi.
} 
O canibalismo explica-se da seguinte maneira: "Não temos feito história da cultura com o pensamento, mas com o sangue, alimentando-nos antropofagicamente do corpo do adversário - eis o complexo canibalista cultural português que nos tem definido" (REAL, 2007, p. 100).

Percebe-se a profunda conexão entre o ensaio A Morte de Portugal e a peça 1755, $o$ Grande Terremoto, que pode ser resumida da seguinte maneira: para entender Portugal é preciso entender Pombal; e, para entendê-lo, é preciso estudar o terremoto. A figura do ministro é determinante de duas características que, segundo o autor, serão importantes para a compreensão do país em sua história e em sua contemporaneidade.

Primeiro, o fato de que o Estado, assim como já afirmara Oliveira Martins, é o motor de toda a sociedade. Nada se faria por meio da complexidade da comunidade, mas, sim, pela vontade do líder. Ele é, além de "distribuidor-mor da riqueza", "o dedo demonstrador do sentido clarificador da História" (REAL, 2007, p. 94).

Segundo, a sociedade não evolui por meio das reformas, mas apenas por rupturas revolucionárias, agindo sempre pela negativização do oposto, estabelecendo sempre uma "doutrina contrária" a ser combatida, em que o diferente é, de pronto, o inimigo.

A continuar dessa maneira, o povo, filho legítimo do país, sem participar das decisões e sem escolher o seu destino, permanecerá sempre na mesma situação.

A figura do Marquês de Pombal é, então, ponto crucial para explicar a história do país e o terremoto flagrante da ascensão do ministro. Portanto, ao entender o passado, luzes são lançadas sobre o presente do país. Espera-se apenas que a escolha não seja permanecer à sombra, mais uma vez.

\section{Referências}

ADAMOUPOLOS, S. Entrevista com Miguel Real. In: Revista Todos os Nomes. $\mathrm{n}^{\circ}$ 837, jun 2008. Disponível em: http://pt.scribd.com/doc/8763235/Miguel-Real-entrevista (Acessado em 06 mai 2011).

AZEVEDO, J. L. de. O Marquês de Pombal e sua época. Lisboa: Clássica Ed., 1990.

MARTINS, O. História de Portugal. Lisboa: Imprensa Nacional, 1988.

MAXWELL, K. Marquês de Pombal. Paradoxo do Iluminismo. RJ: Paz e Terra, 1996.

PAICE, E. A ira de Deus. Rio de Janeiro: Record, 2010.

REAL, M. A morte de Portugal. Porto: Campo das Letras, 2007. 
REAL, M. e OLIVEIRA, F. 1755 O grande terremoto. Lisboa: Europress, 2006.

SARAIVA, J. H. História concisa de Portugal. $17^{\text { }}$ ed. Lisboa: Europa América, 1995. SERRÃO, J. V.(org.). O terremoto de 1755. Lisboa: Horizonte, 2007.

SOARES, Á. T.. O Marquês de Pombal. Brasília: Universidade de Brasília, 1983. 